$\xi=$

\title{
Prevalence of insomnia and its associated factors among rural elderly: a community based study
}

\author{
Abdel-Hady El-Gilany ${ }^{1}$, Nadia Mohamed Hassan Saleh ${ }^{2}$ *, Heba Noshy Abd El-Aziz Mohamed ${ }^{2}$, \\ Eman Baleegh Meawad Elsayed ${ }^{2}$ \\ ${ }^{1}$ Professor of Public health - Faculty of Medicine -Mansoura University - Egypt \\ ${ }^{2}$ Lecturer of Grontological Nursing- Faculty of Nursing -Mansoura University - Egypt \\ *Corresponding author E-mail: Nado2220@yahoo.com
}

\begin{abstract}
Background: Insomnia is a common problem among older adults and can lead to several complications affecting the quality of life of elderly people.

Aim: To estimate the prevalence of insomnia and its associated factors among community-dwelling elderly.

Study design: This is a cross-sectional descriptive study carried out on 1059 elderly living in three villages affiliated to Mansoura District, Egypt. Data collected during an interview included: socio-demographic and clinical features, habits before sleeping, environmental factors that could affect sleeping, the geriatric depression scale and Athens insomnia scale. Logistic regression analysis was done to find out the independent predictors of insomnia.

Results: The prevalence of insomnia was $62.1 \%$. The logistic regression revealed that insomnia is less likely among elderly of 75 and more $(\mathrm{AOR}=0.3)$ compared to those aged 60-75 years. The risk of insomnia is high among those with depression $(\mathrm{AOR}=6.4$ and 14.6 for mild and moderate/severe depression; respectively), fear of death $(\mathrm{AOR}=14.7)$, life stressors $(\mathrm{AOR}=7.1)$, presence of musculoskeletal disorders ( $\mathrm{AOR}=5.6$ ), respiratory disorders $(\mathrm{AOR}=4.5)$, worry about children $(\mathrm{AOR}=4.5)$ and cold bedroom $(\mathrm{AOR}=2.7)$.

Conclusion: Slightly less than two-thirds of the studied subjects have insomnia, and most of the associated factors are preventable and/or controllable.

Recommendations: According to the results of the present study, the following recommendations are suggested: Design educational program for elders to enhance sleep through emphasizing on the importance of sleep hygiene practice, behavioral and nonpharmacological interventions, and healthy lifestyle.
\end{abstract}

Keywords: Insomnia; Elderly; Risk Factors; Prevalence; Rural.

\section{Introduction}

Sleep is one of the important aspects of life, and it allocates onethird of everybody's life span. Insomnia is one of the most important sleep problems among older adults. It is a chronic or acute sleep disorder characterized by a subjective complaint of difficulty initiating, and/or maintaining sleep, poor-quality sleep, or inadequate sleep duration (Kamel, Gammack, 2006; Buysse, 2011; Passos, 2011). Previous studies reported prevalence rates of sleep disorders to be ranged from $42 \%$ to $80 \%$ among elderly (Sukying, 2003; Shives, 2004; Tablosky, 2006; Rongve, 2010; Hosseini et al, 2011; Chen, 2012; Tsou, 2013). In Egypt, a study done among elderly living in a community in Alexandria City; reported that the prevalence of insomnia was $33.4 \%$ (Makhlouf, 2007). Several changes that occur with the aging increase the risk for sleep problems, including comorbidity, greater medications use, age-related changes in various circadian rhythms, and environmental and lifestyle changes (Roepke, 2010).

However, previous studies suggested that sleep disturbances in the elderly may arise from a variety of psychosocial and biologic factors rather than aging (Tanaka, 2002; Shives, 2004; Rwin, 2008). Specifically, retirement from work generally results in fewer daily scheduled events, which may influence the timing of sleep and napping. Many aged individuals develop various health conditions such as nocturia, arthritis, headache, gastrointestinal illness, bronchitis, cardiovascular symptoms, diabetes, menopause, stroke, dementia, and depression, all of which have been shown to disrupt sleep in the aged (Hosseini, 2011).

Furthermore, medication side effects, physical disabilities, cognitive brittleness, reduced coping skills, death or disabilities of the spouse, financial strain, and stressful life events all may induce dysphoria, which then may result in sleep disturbances (Liu, 2005). The Gerontological nurse must understand normal sleep patterns and be able to identify common age-related changes in sleep patterns and common sleep disorders, to assess, plan, intervene, and evaluate appropriately and effectively. Also she should know the risk factors in order to apply appropriate measures based on accurate analysis for the problem (Reid, 2010; Morin, Benca, 2012). In Egypt, there is a dearth of information about sleep disorders among elderly specially those living in rural communities. Therefore, this study was carried out to determine the prevalence and the factors associated with insomnia among community dwelling rural elderly.

\section{Aim of the study}

To determine the prevalence and the factors associated with insomnia among community dwelling rural elderly. 


\section{Research question}

What are the prevalence and factors associated with insomnia among community dwelling rural elderly?

\section{Subjects and method}

\subsection{Research design}

A cross-sectional descriptive design was used in this study.

\subsection{Setting}

It was carried out during period from May 1 to October 31, 2016 in three randomly selected villages (Awesh El-Hagar, Shoha and Menyet Sandoub) from 23 villages affiliated to El -Mansoura District, Egypt.

\subsection{Subjects or sample}

The target population is elderly of 60 years or more, of both sexes and able to comprehend and communicate.

Sample size was calculated by using (https://www.dssresearch.com/KnowledgeCenter/toolkitcalculator s/samplesizecalculators.aspx). A previous study in Egypt found that the prevalence of insomnia among the elderly $=33.6 \%$ (Shokry, 2014), with alpha error $=5 \%$, study power $=80 \%$ and precision of $5 \%$, the expected sample size should be 1059 . These were distributed proportionally between the three villages according to the number of elderly registered in the local Family Medicine Centers (377 from Awesh El-Hagar, 352 from Shoha and 330 from Menyet Sandoub). From each village, elders were selected from the family files using a systematic random sample. Data was collected during an interview with the elderly at their home on a mutually agreed day and time as arranged by rural leader (Rayda Refia) affiliated to the local Family Medicine Center.

\subsection{Tools for data collection}

Tool 1: Study questionnaire covered the socio-demographic data, medical history of chronic diseases, habits before sleeping and environmental condition of sleeping room.

Tool II: The geriatric depression scale (GDS) short form:

This scale was developed by Sheikh and Yesavage (1986). It is 15 items self-reported instrument, used in the present study to assess depression and general wellbeing of the elderly. The scale was translated into Arabic and approved to be valid and reliable by Elhuseiny (2013). The older adult chooses the best answer either yes: one (1) or No: zero (0) for how he/ she has felt over the last week. From the 15 questions, 10 questions were indicating the presence of depression when answered positively, while the rest (question numbers $1,5,7,11,13$ ) were indicating depression when answered negatively. Scores ranges from zero to 15 , items are summed for total scores. Score from zero to 4 indicates no depression, score from 5 to 8 was indicating mild depression, and score from 9 to 11 was indicating moderate depression and score from 12 to 15 indicates severe depression.

Tool III: Athens insomnia scale (AIS):

This scale was developed by Soldatos et al. (2000). It is originally designed to assess the degree of insomnia through a detailed sleeping history during the last month. It was translated into Arabic and approved to be valid and reliable by Shokry, 2014; the inter-rater correlation coefficient of different items ranged from 0.7 to 0.9 with Cronbach's alpha of 0.73 . The scale includes eight elements. The first five elements cover night-time symptoms of insomnia while the last three elements ask for daytime consequences of disturbed sleep. The eight elements of this scale were ranked from zero (0) to (3), where zero (0) indicates no problem and 3 indicate very serious problem. The study subjects are asked to determine the severity of the complaints (absent $=0$, mild $=1$, severe $=2$, and very severe $=3$ ). The study subject who had a score of 6 or higher was considered as a positive case for insomnia.

\subsection{Validity and reliability}

The study tools were revised by seven experts (staff) in the field of gerontological nursing, psychiatric and mental health nursing, as a jury to test its content validity and feasibility, and the necessary modifications were done.

\subsection{Pilot study}

A pilot study was carried out on 20 elderly selected from El Baramon village, Mansoura to test clarity and feasibility of the tools; and the approximate time needed for the interview.

\subsection{Ethical considerations}

The study was approved by the Research Ethics Committee of the Faculty of Nursing, Mansoura University. An official permission was obtained from the directors of the Family Medicine Center in each village. Verbal consent was obtained from elderly persons after complete description of the purpose and nature of the study. Confidentiality of data, privacy was assured, and they were informed that data collected will be used only for the research purpose.

\section{Limitations of the study}

The possibility of recall bias cannot be excluded as there is no documented diagnosis of insomnia. Urban elderly were not included due to difficulty in approaching them. A national largescale study will provide the full of insomnia in elderly.

\section{Data analysis}

Data were analyzed using SPSS (Statistical Package for Social Sciences) version 20. Variables were presented as number ofand percent. Chi square was used to test the significance in bivariate analysis and crude odds ratios (CRO) and their 95\% CI were calculated. Variables significantly associated with depression were entered into a multivariate logistic regression model using forward Wald method. Adjusted OR and their 95\% CI were calculated. $\mathrm{P} \leq 0.05$ was considered statistically significant.

\section{Results}

The age of study subjects ranged from 60 to 91 years with a mean of $67.24 \pm 7.14$ years.

Table (1): Show that, the prevalence of insomnia is $62.1 \%$ of the study subjects. The prevalence of insomnia is significantly lower in older age groups and those with just enough income $(\mathrm{COR}=0.6)$ However it is significantly higher in females $(\mathrm{COR}=2.0)$, housewives $(\mathrm{COR}=2.1)$, elderly living alone $(\mathrm{COR}=2.5)$ and still working elders $(\mathrm{COR}=2.4)$

Table (2): Revealed that the presence of morbidities is associated with an increased risk of insomnia, COR were 2.1, 4.4, 2.2, 3.8, 11.5 and 6.3 for cardiovascular, musculoskeletal, gastrointestinal, urological and neurological disorders; respectively

Table (3): Shows that the risk of insomnia is higher with cold sleeping rooms $(\mathrm{COR}=3.7)$. Furthermore, day naps, night medication and changing clothes due to incontinence are associated with more risk of insomnia (COR=1.5, 25.2 and 3.0; respectively).

Table (4): Reveals that life stressors, worry about children, fear of death, fear of thieves, bad dreams, responsibilities/duties, mild depression, moderate/severe depression and caffeinated drinks before sleep are associated with increased risk of insomnia $(\mathrm{COR}=11.9,7.2,13.2,15.5,2 ., 11.5,55.4$ and 1.4; respectively). 
However, night praying is associated with lower risk of insomnia $(\mathrm{COR}=0.6)$.

Table (5): The logistic regression revealed that the independent predictors of insomnia are older age groups $(\mathrm{AOR}=0.3)$, musculoskeletal disorders $(\mathrm{AOR}=5.6)$, respiratory disorders $(\mathrm{AOR}=4.5)$, cold sleeping room $(\mathrm{AOR}=2.7)$, life stressors $(\mathrm{AOR}=7.1)$, worry about children $(\mathrm{AOR}=4.5)$, fear of death $(\mathrm{AOR}=14.7)$, mild depression $(\mathrm{AOR}=6.7)$ and moderate/severe depression $(\mathrm{AOR}=14.6)$.

Table 1: Prevalence of Insomnia and Its Variation with Socio-Demographic Characteristics of the Study Subjects

\begin{tabular}{|c|c|c|c|c|}
\hline & Total & $\begin{array}{l}\text { Insomnia } \\
\mathrm{N}(\%)\end{array}$ & $\mathrm{P}$ & $\operatorname{COR}(95 \% \mathrm{CI})$ \\
\hline Overall & 1059 & $658(62.1)$ & & \\
\hline \multicolumn{5}{|l|}{ Age (years): } \\
\hline $60-$ & 881 & $587(66.6)$ & & $1(\mathrm{r})$ \\
\hline $75-$ & 135 & $59(43.7)$ & $\leq 0.001$ & $0.4(0.3-0.6)$ \\
\hline $85+$ & 43 & $12(27.9)$ & $\leq 0.001$ & $0.2(0.1-0.4)$ \\
\hline \multicolumn{5}{|l|}{ Sex: } \\
\hline Male & 531 & $286(53.9)$ & & $1(\mathrm{r})$ \\
\hline Female & 528 & $372(70.5)$ & $\leq 0.001$ & $2.0(1.6-2.6)$ \\
\hline \multicolumn{5}{|l|}{ Marital status: } \\
\hline -Married & 641 & $395(61.6)$ & & $1(\mathrm{r})$ \\
\hline -Widow & 383 & $236(61.6)$ & 0.0 & $1.0(0.8-1.3)$ \\
\hline -Others* & 35 & $27(77.1)$ & 0.06 & $2.1(0.9-4.7)$ \\
\hline \multicolumn{5}{|l|}{ Level of education: } \\
\hline -Illiterate & 591 & $367(62.1)$ & & $1(\mathrm{r})$ \\
\hline -Read and write & 290 & $187(64.5)$ & 0.5 & $1.1(0.8-1.5)$ \\
\hline -Basic education & 65 & $38(58.5)$ & 0.6 & $0.9(0.5-1.4)$ \\
\hline -Secondary education & 71 & $42(59.2)$ & 0.4 & $0.8(0.4-1.5)$ \\
\hline -University education & 42 & $24(57.1)$ & 0.5 & $0.8(0.4-1.5)$ \\
\hline \multicolumn{5}{|c|}{ Occupation before retirement: } \\
\hline -Farmers & 165 & $86(52.1)$ & & $1(\mathrm{r})$ \\
\hline -Employees & 314 & $179(57.0)$ & 0.3 & $1.2(0.8-1.8)$ \\
\hline -Housewives & 449 & $311(69.3)$ & $\leq 0.001$ & $2.1(1.4-3.0)$ \\
\hline -Others & 131 & $82(62.6)$ & 0.07 & $1.5(0.96-2.5)$ \\
\hline \multicolumn{5}{|l|}{ Living condition: } \\
\hline -Own home with family & & & & $1(\mathrm{r})$ \\
\hline -Own home alone & 634 & $389(61.4)$ & $\leq 0.001$ & $2.5(1.6-3.9)$ \\
\hline -With sons/relatives & $\begin{array}{l}155 \\
270\end{array}$ & $\begin{array}{l}124(80.0) \\
145(53.7)\end{array}$ & 0.03 & $0.7(0.5-0.97)$ \\
\hline \multicolumn{5}{|l|}{ Income: } \\
\hline -Not Enough & 483 & $329(68.1)$ & & $1(\mathrm{r})$ \\
\hline -Enough & 535 & $302(56.4)$ & $\leq 0.001$ & $0.6(0.5-0.8)$ \\
\hline -Enough and safe & 41 & $27(65.9)$ & 0.09 & $0.9(0.5-1.8)$ \\
\hline \multirow{2}{*}{$\begin{array}{l}\text { Still working: --No } \\
\text {-Yes }\end{array}$} & 1020 & $627(61.5)$ & \multirow[b]{2}{*}{0.023} & $1(\mathrm{r})$ \\
\hline & 39 & $31(79.5)$ & & $2.4(1.1-5.3)$ \\
\hline
\end{tabular}

*Single, divorced $\&$ separated $\mathrm{COR}=$ crude odds ratio $\mathrm{CI}=$ Confidence interval

Table 2: Variation of the Prevalence of Insomnia According to Clinical Data of the Study Subjects

\begin{tabular}{|c|c|c|c|c|}
\hline & Total & Insomnia N(\%) & Significance & COR(95\% CI) \\
\hline $\begin{array}{l}\text { Cardiovascular disorders: } \\
\text { No } \\
\text { Yes }\end{array}$ & $\begin{array}{l}640 \\
419\end{array}$ & $\begin{array}{l}355(55.5) \\
303(72.3)\end{array}$ & $\leq 0.001$ & $\begin{array}{l}1(\mathrm{r}) \\
2.1(1.6-2.7)\end{array}$ \\
\hline $\begin{array}{l}\text { Endocrine disorders: } \\
\text { No } \\
\text { Yes }\end{array}$ & $\begin{array}{l}768 \\
291\end{array}$ & $\begin{array}{c}467(60.8) \\
191(65.8)\end{array}$ & 0.15 & $\begin{array}{l}1(\mathrm{r}) \\
1.2(0.9-1.6)\end{array}$ \\
\hline $\begin{array}{l}\text { Musculoskeletal disorders: } \\
\text { No } \\
\text { Yes }\end{array}$ & $\begin{array}{l}896 \\
163\end{array}$ & $\begin{array}{l}518(57.8) \\
140(85.9)\end{array}$ & $\leq 0.001$ & $\begin{array}{l}1(\mathrm{r}) \\
4.4(2.8-7.0)\end{array}$ \\
\hline $\begin{array}{l}\text { Gastrointestinal disorders: } \\
\text { No } \\
\text { Yes }\end{array}$ & $\begin{array}{l}947 \\
114\end{array}$ & $\begin{array}{l}572(60.4) \\
86(76.8)\end{array}$ & 0.001 & $\begin{array}{l}1(\mathrm{r}) \\
2.2(1.4-3.4)\end{array}$ \\
\hline $\begin{array}{l}\text { Respiratory disorders: } \\
\text { No } \\
\text { Yes }\end{array}$ & $\begin{array}{l}985 \\
74\end{array}$ & $\begin{array}{l}595(60.4) \\
63(85.4)\end{array}$ & $\leq 0.001$ & $\begin{array}{l}1(\mathrm{r}) \\
3.8(2.0-7.2)\end{array}$ \\
\hline $\begin{array}{l}\text { Urological disorders: } \\
\text { No } \\
\text { Yes }\end{array}$ & $\begin{array}{l}1021 \\
38\end{array}$ & $\begin{array}{l}622(60.9) \\
36(94.7)\end{array}$ & $\leq 0.001$ & $\begin{array}{l}1(\mathrm{r}) \\
11.5(2.8-48.2)\end{array}$ \\
\hline $\begin{array}{l}\text { Neurological disorders: } \\
\text { No } \\
\text { Yes }\end{array}$ & $\begin{array}{l}1037 \\
22\end{array}$ & $\begin{array}{l}638(61.5) \\
20(90.9)\end{array}$ & 0.005 & $\begin{array}{l}1(\mathrm{r}) \\
6.3(1.5-26.9)\end{array}$ \\
\hline $\begin{array}{l}\text { Ophthalmological disorders } \\
\text { No } \\
\text { Yes }\end{array}$ & $\begin{array}{l}1044 \\
15\end{array}$ & $\begin{array}{l}647(62.0) \\
11(73.3)\end{array}$ & 0.4 & $\begin{array}{l}1(\mathrm{r}) \\
1.7(0.5-5.3)\end{array}$ \\
\hline $\begin{array}{l}\text { Cancer: No } \\
\text { Yes }\end{array}$ & $\begin{array}{l}1049 \\
10\end{array}$ & $\begin{array}{c}148(43.8) \\
10(100.0)\end{array}$ & 0.013 & $\begin{array}{l}\text { 1(r) } \\
\text { Undefined }\end{array}$ \\
\hline
\end{tabular}

$\mathrm{COR}=$ crude odds ratio $\mathrm{CI}=$ Confidence interval 
Table 3: Variation of the Prevalence of Insomnia According To Environmental Factors and Personal Habits of the Study Subjects

\begin{tabular}{|c|c|c|c|c|}
\hline & Total & $\begin{array}{l}\text { Insomnia } \\
\mathrm{N}(\%)\end{array}$ & Significance & $\operatorname{COR}(95 \% \mathrm{CI})$ \\
\hline \multicolumn{5}{|c|}{ Environmental factors } \\
\hline \multicolumn{5}{|c|}{ Noise: } \\
\hline No & 582 & $357(61.3)$ & \multirow[b]{2}{*}{0.6} & \multirow[b]{2}{*}{$1(\mathrm{r}) 1.1(0.8-1.4)$} \\
\hline Yes & 477 & $301(63.1)$ & & \\
\hline \multicolumn{5}{|c|}{ Hot sleeping room: } \\
\hline No & 679 & $419(61.7)$ & \multirow{2}{*}{0.7} & $1(\mathrm{r})$ \\
\hline Yes & 380 & $239(62.9)$ & & $1.1(0.8-1.4)$ \\
\hline Cold sleeping room: No & 877 & $505(57.6)$ & \multirow[b]{2}{*}{$\leq 0.001$} & $1(r)$ \\
\hline Yes & 182 & $182(84.1)$ & & $3.7(2.5-5.6)$ \\
\hline \multicolumn{5}{|c|}{ Excess lighting: } \\
\hline No & 889 & $549(61.8)$ & \multirow[b]{2}{*}{0.6} & $1(\mathrm{r})$ \\
\hline Yes & 170 & $109(64.1)$ & & $1.1(0.8-1.6)$ \\
\hline \multicolumn{5}{|c|}{ Uncomfortable bed: } \\
\hline No & 975 & $600(61.5)$ & \multirow{2}{*}{0.17} & $1(\mathrm{r})$ \\
\hline Yes & 84 & $58(69.0)$ & & $1.4(0.9-2.3)$ \\
\hline No & 1024 & $633(61.8)$ & \multirow{2}{*}{0.2} & $1(\mathrm{r})$ \\
\hline Yes & 35 & $25(71.4)$ & & $1.5(0.7-3.3)$ \\
\hline \multicolumn{5}{|c|}{ Snoring: } \\
\hline No & 1021 & $633(61.8)$ & \multirow{2}{*}{0.2} & $1(\mathrm{r})$ \\
\hline Yes & 38 & $25(71.4)$ & & $1.2(0.6-2.3)$ \\
\hline \multicolumn{5}{|c|}{ Shared bed: } \\
\hline No & 1040 & $643(61.8)$ & \multirow{2}{*}{0.13} & $1(\mathrm{r})$ \\
\hline Yes & 19 & $15(78.9)$ & & $2.3(0.8-7.0)$ \\
\hline \multicolumn{5}{|c|}{ Personal habits } \\
\hline \multicolumn{5}{|c|}{ Day naps: } \\
\hline No & 665 & $389(58.5)$ & \multirow{2}{*}{0.002} & $1(\mathrm{r})$ \\
\hline Yes & 394 & $269(68.3)$ & & $1.5(1.2-2.0)$ \\
\hline \multicolumn{5}{|c|}{ Taking medication at night } \\
\hline No & & & \multirow[b]{2}{*}{$\leq 0.001$} & $1(\mathrm{r})$ \\
\hline Yes & $\begin{array}{l}1019 \\
40\end{array}$ & $\begin{array}{l}619(60.7) \\
39(97.5)\end{array}$ & & $25.2(3.4-184.2)$ \\
\hline \multicolumn{5}{|c|}{ Changing clothes due to incontinence: } \\
\hline
\end{tabular}

$\mathrm{COR}=$ crude odds ratio $\mathrm{CI}=$ Confidence interval

Table 4: Variation of he Prevalence of Insomnia According to Psychological Factors and Habits Before Bed Time

\begin{tabular}{|c|c|c|c|c|}
\hline & Total & Insomnia N(\%) & Significance & $\operatorname{COR}(95 \% \mathrm{CI})$ \\
\hline \multicolumn{5}{|l|}{ Psychological factors } \\
\hline \multicolumn{5}{|l|}{ Life stressors: } \\
\hline No & 805 & $422(52.4)$ & \multirow{2}{*}{$\leq 0.001$} & $1(\mathrm{r})$ \\
\hline Yes & 254 & $236(92.9)$ & & $11.9(7.2-19.6)$ \\
\hline \multicolumn{5}{|l|}{ Worry about children: } \\
\hline No & 643 & $299(46.5)$ & \multirow{2}{*}{$\leq 0.001$} & $1(\mathrm{r})$ \\
\hline Yes & 416 & $359(86.3)$ & & $7.2(5.3-10.0)$ \\
\hline Praying: No & 757 & $494(65.3)$ & & $1(\mathrm{r})$ \\
\hline Yes & 302 & $164(54.3)$ & $\leq 0.001$ & $0.6(0.5-0.8)$ \\
\hline \multicolumn{5}{|l|}{ Fear of death: } \\
\hline No & 857 & $468(54.6)$ & \multirow{2}{*}{$\leq 0.001$} & $1(\mathrm{r})$ \\
\hline Yes & 202 & $190(94.1)$ & & $13.2(7.2-22.9)$ \\
\hline Fear of thieves: No & 987 & $589(59.7)$ & \multirow[b]{2}{*}{$\leq 0.001$} & $1(\mathrm{r})$ \\
\hline Yes & 72 & $69(95.8)$ & & $15.5(4.9-49.7)$ \\
\hline Bad dreams: No & 994 & $605(60.9)$ & & $1(\mathrm{r})$ \\
\hline Yes & 65 & $53(81.5)$ & $\leq 0.001$ & $2.8(1.5-5.4)$ \\
\hline \multicolumn{5}{|c|}{ Responsibilities/duties: } \\
\hline No & 1018 & $617(60.6)$ & \multirow{2}{*}{$\leq 0.001$} & $1(\mathrm{r})$ \\
\hline Yes & 41 & $41(100.0)$ & & Undefined \\
\hline \multicolumn{5}{|l|}{ Lack of privacy: } \\
\hline No & 1001 & $622(62.1)$ & \multirow{2}{*}{1.0} & $1(\mathrm{r})$ \\
\hline Yes & 58 & $36(62.1)$ & & $1.0(0.6-1.7)$ \\
\hline Depression: No & & & & $1(\mathrm{r})$ \\
\hline Mild & $\begin{array}{l}552 \\
438\end{array}$ & $\begin{array}{l}208(37.7) \\
383(87.4)\end{array}$ & $\leq 0.001$ & $11.5(8.3-16.0)$ \\
\hline Moderate/Severe & $\begin{array}{l}438 \\
69\end{array}$ & $\begin{array}{l}383(87.4) \\
67(97.1)\end{array}$ & $\leq 0.001$ & $55.4(13.4-228.5)$ \\
\hline \multicolumn{5}{|c|}{ Habits before bed time } \\
\hline \multicolumn{5}{|c|}{ Drinking water: } \\
\hline No & 558 & 334(59.9) & \multirow{2}{*}{0.11} & $1(\mathrm{r})$ \\
\hline Yes & 501 & $324(64.7)$ & & $1.2(1.0-1.6)$ \\
\hline \multicolumn{5}{|l|}{ Eating: } \\
\hline No & 658 & $410(62.3)$ & \multirow{2}{*}{0.99} & $1(\mathrm{r})$ \\
\hline Yes & 401 & $248(61.8)$ & & $0.98(0.8-1.3)$ \\
\hline \multicolumn{5}{|c|}{ Watching TV and reading: } \\
\hline No & 685 & $419(61.7)$ & \multirow{2}{*}{0.4} & $1(\mathrm{r})$ \\
\hline Yes & 374 & $239(63.9)$ & & $1.1(0.9-1.5)$ \\
\hline
\end{tabular}




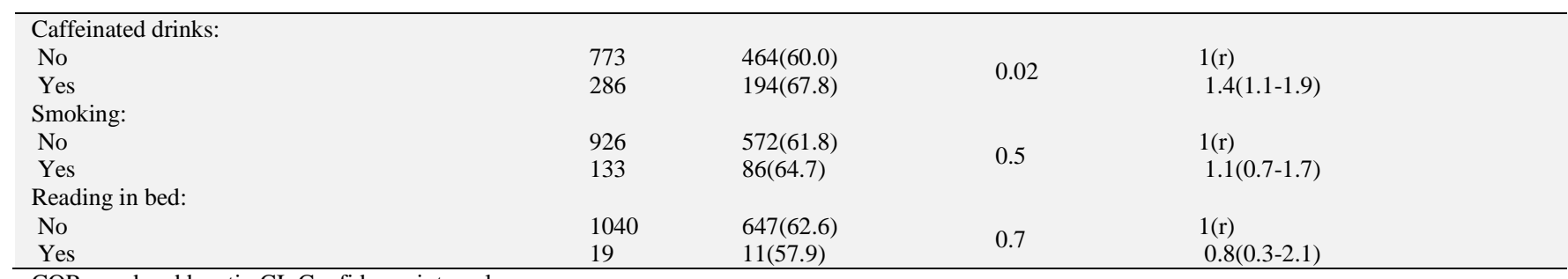

Table 5: Multivariate logistic regression analysis of independent predictors of insomnia

\begin{tabular}{|c|c|c|c|}
\hline & $\beta$ & $\mathrm{P}$ & $\operatorname{AOR}(95 \% \mathrm{CI})$ \\
\hline Age (years): 60- & - & & $1(\mathrm{r})$ \\
\hline $75-$ & -1.1 & $\leq 0.001$ & $0.3(0.2-0.6)$ \\
\hline $85+$ & -1.1 & 0.039 & $0.3(0.1-0.9)$ \\
\hline \multicolumn{4}{|l|}{ Musculoskeletal disorders: } \\
\hline No & - & & $1(\mathrm{r})$ \\
\hline Yes & 1.7 & $\leq 0.001$ & $5.6(3.1-10.2)$ \\
\hline \multicolumn{4}{|l|}{ Respiratory disorders: } \\
\hline No & - & & $1(\mathrm{r})$ \\
\hline Yes & 1.5 & $\leq 0.001$ & $4.5(2.0-10.3)$ \\
\hline Coldness: & - & & $1(r)$ \\
\hline No & 098 & & $\begin{array}{l}1(\mathrm{I}) \\
7(15-46)\end{array}$ \\
\hline Yes & 0.98 & $\leq 0.001$ & $2.7(1.5-4.6)$ \\
\hline Life stressors: & - & & $1(\mathrm{r})$ \\
\hline No & 20 & & $7.1(4.0-12.9)$ \\
\hline Yes & 2.0 & $\leq 0.001$ & \\
\hline \multicolumn{2}{|l|}{ Worry about children: } & & $1(\mathrm{r})$ \\
\hline No & 1.5 & $\leq 0.001$ & $4.5(3.0-6.8)$ \\
\hline \multirow{2}{*}{\multicolumn{4}{|c|}{ Fear of death: }} \\
\hline & - & & $1(\mathrm{r})$ \\
\hline No & 2.7 & $\leq 0.001$ & $14.7(7.4-29.3)$ \\
\hline \multirow{2}{*}{\multicolumn{4}{|c|}{ Depression: }} \\
\hline & - & & $1(\mathrm{r})$ \\
\hline $\begin{array}{l}\text { No } \\
\text { Mild }\end{array}$ & 1.9 & $\leq 0.001$ & $6.7(4.5-10.0)$ \\
\hline $\begin{array}{l}\text { Mild } \\
\text { Moderate/Severe }\end{array}$ & 2.7 & $\leq 0.001$ & $14.6(3.2-65.8)$ \\
\hline Constant & -1.6 & & \\
\hline Model $\chi 2$ & 652.6 & & \\
\hline Per cent correctly corrected & 82.9 & & \\
\hline
\end{tabular}

$\mathrm{AOR}=$ Adjusted odds ratio $\mathrm{CI}=$ Confidence interval.

\section{Discussion}

Insomnia is highly prevalent, especially at advanced age (Altena, 2010, Leger, 2010). Several factors, such as gender, age, socioeconomic status have been associated with the prevalence of insomnia. Aging is another significant factor associated with increased prevalence of insomnia (Ohayon 2002). Therefore, this study was carried out to determine the prevalence, and the factors associated with insomnia among community dwelling rural elderly. The present study revealed a high prevalence of insomnia among the studied subjects $(62.1 \%)$. This proposes that insomnia should be deliberated for an important public health issue for elderly people. This result is in agreement with previous findings (Reid, 2006; Makhlouf, 2007; Enomoto, et al, 2010, Sabry, 2010, Jaussent, 2011). However, other studies in urban localities in Egypt reported a much lower rate of insomnia down to $33.4 \%$ (Bakr, 2012; Saber, 2013 and Shokry, 2014). This contradiction cloud be explained by differences in the socio-demographic characteristics of studied elderly.

The present study revealed that the risk of insomnia decreased significantly among older elderly compared to young elderly ( $\mathrm{AOR}=0.3$ ). It is can be rationalized by that the young elderly had some responsibilities and duties as housekeeping activities, providing care to their family members, and some of them especially male are still working. These findings come in agreement with some studies (Su, 2004; Tsou, 2013; Shokry, 2014). In contrast other studies reported significant association between increasing the age and sleeping quality and insomnia (Makhlouf, 2007; Wong, 2011; El Kady, 2012). However, Adetola et al (2014) found no association between age and insomnia.

Insomnia and other sleep disorders can occur as a consequence of chronic diseases. Chronic diseases correlate closely with various sleep disturbances in older adults. Medical conditions associated with chronic pain (e.g. arthritis, back pain), cardiovascular disease (heart failure), respiratory diseases, are known to be associated with chronic insomnia (Taylor et al, 2007). Moreover, the result of the present study is a good example of the reciprocal relationship between insomnia and health problems. As the subjects with chronic medical problems, especially musculoskeletal and respiratory disorders had a higher risk of insomnia than those without chronic medical problem. This can be explained by that insomnia may be associated with the symptoms of the chronic diseases or due to side effects of the drugs used to control them (Fernandez, 2002; Bloom, 2002 and Jaussent, 2011). These results agree with other studies (Anderson, 2006; Makhlouf, 2007; Shokry, 2014, Weronika et al, 2016).

Environmental conditions particularly uncomfortable low temperature can be problematic for older adults and significantly influence sleep patterns. The current study findings revealed that, the elderly who had feeling of coldness experiences insomnia than those who haven't. This in accordance with a study done in Egypt by Shokry (2014) who reported that coldness is the most environmental factors affecting the sleep.

Stress is an important issue related to insomnia (Akersted, 2006). The occurrence of stressful life events has been shown to be strongly associated to chronic insomnia (Robaina et al., 2009). The results from this study have shown that older people who are exposed to the pressures of life, and have worry over their children had a higher risk of insomnia compared with the elderly who are not exposed to these pressures. It is possible that the life stressors are associated with difficulty falling asleep, frequent arousals during the night and difficult returning to sleeping, which makes the elderly, anxious and frustrated. This is in agreement with other studies conducted by Makhlouf (2007), Morphy et al, 2007 
Furihata (2011) and Leblanc (2015) who reported that insomnia was significantly correlated with daily stress events.

Death generates attitudes such as fear and anxiety for the majority of elders. The fear of death is a concept that is occurred in the dying process, and includes the fear of death itself and what happens after it. Some of the elderly think that waiting for death worse than death itself (Lehto, 2009). The present study revealed that the elderly who reported that they have fear of death are significantly associated with high risk of insomnia than those who haven't. This is in agreement with previous studies (Cacioppo et al., 2002; Stromberg 2008; Fitzsimons 2007; Suguna et al, 2015).

Depression is one of the most common psychiatric disorders among the elderly. It is a disabling pathological condition that is hugely damaging to the functional and social lives of elderly. Depression may also be strongly associated with sleep problems; people who are depressed take longer time to fall asleep (Hirst, 2015 and Gonzalez, 2016). The current study revealed that, the elderly who reported moderate and severe depression had a greater risk of insomnia than those who have mild depression. The depressed elderly may have less deep sleep; awaken more frequently during the night and earlier in the morning and feel less rested in the morning. This result is in agreement with other studies conducted (Makhlouf, 2007; Khater, 2008; Botts, 2009; Tsou, 2013; Shokry 2014).

\section{Conclusion}

Nearly two-thirds of the studied subjects have insomnia that is associated with multiplicity of preventive and/or controllable factors. Early detection and treatment of morbidities, especially musculoskeletal, respiratory disorders and depression will contribute to prevention of insomnia. Suitable temperature of sleeping room, control of life stressors, keeping children away from elderly during sleep and religious and psychiatric treatment of fear of death, all these will contribute to further prevention of insomnia. Special attention should be paid to be younger elderly. The nurse has an important and active role in teaching and motivating the elderly persons to participate in the exercise program, by emphasizing the benefits in terms of improves quality of life, maintaining and increasing functional abilities, improving flexibility and strength and improves sleep quality of the elderly.

\section{Recommendations}

According to the results of the present study, the following recommendations are suggested:

- Design educational program for elders to enhance sleep through emphasizing on the importance of sleep hygiene practice, behavioral and non-pharmacological interventions, and healthy lifestyle.

- In-service training program to all care providers about importance of sleep and the avoidance of risk factors of insomnia, and should take these factors into consideration, when dealing with older adults complain from insomnia and plan for adequate management of these factors may help in overcoming insomnia and its complication.

\section{Acknowledgements}

The authors are thankful to all elders from each village who are participating in this study also they appreciate help provided by directors and rural leaders (Rayda Refia) affiliated to each local Family Medicine Center in conduction of the study.

\section{References}

[1] Adetola M O, Lawrence A A, Olufemi O O, Mayowa O \& Adesola O (2014) Factors Associated with Insomnia among Elderly Patients Attending a Geriatric Centre in Nigeria Current Gerontology and
Geriatrics. Article ID 780535, 10 pages https://doi.org/10.1155/2014/780535.

[2] Akerstedt T (2006) psychosocial stress and impaired sleep, Scandinavian Journal of Work, Environment \& Health. 32 (6): 493-501. https://doi.org/10.5271/sjweh.1054.

[3] Altena E, Vrenken H, VanDerWerf YD, vandenHeuvel OA \& VanSomeren JW (2010) Reduced Orbitofrontal and Parietal Gray Matter in Chronic Insomnia: A Voxel-Based Morphometric Study. Biology Psychiatry. 67: 182-185. https://doi.org/10.1016/j.biopsych.2009.08.003.

[4] Anderson G (2006) The Growing Burden of Chronic Disease in American. Public Health Reports 119-123.

[5] Bakr I M, AbdElaziz K M, Abou El Ezz N F \& Fahim H I (2012) Insomnia in institutionalized older people in Cairo, Egypt: Prevalence and risk factors associated. European Geriatric Medicine 3(2): 92-96. https://doi.org/10.1016/j.eurger.2012.02.002.

[6] Bloom BJ, Owens JA, \& McGuinn M (2002) Sleep and its relation to pain, dysfunction, and disease activity in juvenile rheumatoid arthritis. Journal of Rheumatology; 29(1):169-73.

[7] Botts EM (2009) The Independent Influence of Anxiety on Insomnia and Sleepiness in Older Adults. University of the Rockies, USA

[8] Buysse DJ, Germain A, Moul DE, Franzen PL, Brar LK \& Fletcher ME (2011) Efficacy of Brief Behavioral Treatment for Chronic Insomnia in Older Adults. Arch Intern Med 171(10): 887-895 https://doi.org/10.1001/archinternmed.2010.535.

[9] Cacioppo J T, Hawkley L C, Berntson G G, Ernst J M, Gibbs A C, Stickgold R \& Hobson J A (2002) Does lonely days invade the nights. Psychological Science 13: $384-\quad 387$. https://doi.org/10.1111/j.0956-7976.2002.00469.x.

[10] Chen YS (2012) Association between chronic insomnia and depression in elderly adults. J Chin Med Assoc 75:195-206. https://doi.org/10.1016/j.jcma.2012.04.001.

[11] El Kady HM, Ibrahim HK \& Mohamed SG (2012) Cognitive behavioral therapy for institutionalized elders complaining of sleep disturbance in Alexandria, Egypt. Sleep Breath 16(4): 1173-1180 https://doi.org/10.1007/s11325-011-0629-3.

[12] Elhusseini S (2013) Effect of self-care intervention on quality of life of older adults with heart failure. Unpublished Doctorate Thesis. Alexandria University, Faculty of Nursing.

[13] Enomoto M, Tsutsui T \& Higashino S1 (2010) Sleep-related problems and use of hypnotics in inpatients of acute hospital wards. General Hospital Psychiatry 32(3): 276-283. https://doi.org/10.1016/j.genhosppsych.2010.01.015.

[14] Fernandez-Fernandez FJ (2002) Treatment of chronic obstructive pulmonary disease. Revista Clinica Espanola 202(9):520.

[15] Fitzsimons D, Mullan D \& Wilson J (2007) the challenge of patients' unmet palliative care needs in the final stages of chronic illness. Palliat 4:313-22. https://doi.org/10.1177/0269216307077711.

[16] Furihata R, Uchiyama M \& Takahashi S (2011) Self-help behaviors for sleep and depression: a Japanese nationwide general population survey. J Affect Disord 130:75-82. https://doi.org/10.1016/j.jad.2010.09.019.

[17] González A, Ignácio Z, Jornada L, Réus G, Abelaira H \& Santos M (2016) Depressive disorders and comorbidities among the elderly: a population-based study. Rio de Janeiro 19(1):95-103 https://doi.org/10.1590/1809-9823.2016.14210.

[18] Hirst S, Lane A \& Miller C (2015) Miller's nursing for wellness in older adults. 7th ed. Philadelphia: Lippincott Williams \&Wilkins pp $502-26$.

[19] Hosseini H, Esfirizi MF, Marandi SM \& Rezaei A (2011) The effect of Ti Chi exercise on the sleep quality of the elderly residents in Isfahan, Sadeghieh elderly home. IJNMR 16(1):55.

[20] Jaussent I, Dauvilliers Y \& Ancelin ML (2011) Insomnia symptoms in older adults: associated factors and gender differences. Am $\begin{array}{lll}\text { J Geriatr } & \text { Psychiatry } & \text { 19(1):88-97 }\end{array}$ https://doi.org/10.1097/JGP.0b013e3181e049b6.

[21] Kamel NS \& Gammack JK (2006) Insomnia in the elderly: cause, approach, and treatment. Am J Med 19(6):463-469. https://doi.org/10.1016/j.amjmed.2005.10.051.

[22] Khater MS, Abou El Ezz NF (2008) Association between cognitive function and chronic insomnia among older adults living in geriatric homes in Cairo, Egypt. Ain Shams Medical Journal 59(7-9): 963-976.

[23] Leblanc M, Desjardins S \& Desgagné A (2015) the relationship between sleep habits, anxiety, and depression in the elderly. National Institute of Health J 7:33-42.

[24] Leger D \& Bayon V (2010) Societal costs of insomnia. Sleep Medicine $\quad$ Reviews 14 : 379-389. https://doi.org/10.1016/j.smrv.2010.01.003. 
[25] Lehto H \& Stein KF (2009) Death anxiety: an analysis of an evolving concept. Res Theory Nurs Pract 23(1):23-41 https://doi.org/10.1891/1541-6577.23.1.23.

[26] Liu X \& Liu L (2005) Sleep habits and insomnia in a sample of elderly persons in China 28(12):1579-1587

[27] Makhlouf MM, Ayoub, AI \& Abdel-Fattah MM (2007) Insomnia symptoms and their correlates among the elderly in geriatric homes in Alexandria, Egypt. Sleep Breath 11:187-194. https://doi.org/10.1007/s11325-006-0097-3.

[28] Morin CM \& Benca R (2012) chronic insomnia. Lancet 379(9821):1129-1141 https://doi.org/10.1016/S01406736(11)60750-2.

[29] Morphy H, Dunn K, Lewis M, Boardman H \& Croft P (2007) Epidemiology of Insomnia: a Longitudinal Study in a UK Population. Musculoskeletal Research Centre 30(3):274-280.

[30] Ohayon MM (2002) Epidemiology of insomnia: what we know and what we still need to learn. Sleep Med Rev 6:97-111. https://doi.org/10.1053/smrv.2002.0186.

[31] Passos GS, Poyares D \& Santana MG (2011) Effects of moderate aerobic exercise training on chronic primary insomnia. Sleep Med 12(10):1018-27. https://doi.org/10.1016/j.sleep.2011.02.007.

[32] Reid KJ, Zoran M, \& Sanford F Sleep (2006) A Marker of Physical and Mental Health in the Elderly. Am J Geriatr Psychiat 14(10):860-866 https://doi.org/10.1097/01.JGP.0000206164.56404.ba.

[33] Reid KJ, Baron KG, Lu B, Naylor E, Wolfe L \& Zee PC (2010) Aerobic exercise improves self-reported sleep and quality of life in older adults with insomnia. Sleep Med 11(9):934-940. https://doi.org/10.1016/j.sleep.2010.04.014

[34] Robaina J R. Lopes C S, Rotenberg L, Faerstein E, Fischer F M Moreno C R, Werneck G L. \& Chor D (2009) Stressful life events and insomnia complaints among nursing assistants from a university hospital in Rio de Janeiro: The Pro- Saude Study, Revista Bra$\begin{array}{lllll}\text { sileira de } & \text { Epidemiologia } 12 & \text { (3): }\end{array}$ https://doi.org/10.1590/S1415-790X2009000300018.

[35] Roepke S, \& Israel S (2010) Sleep disorders in the elderly. Indian j med res 131: 302-10.

[36] Rongve A, Boeve BF \&, Aarsland D (2010) correlates of caregiver-reported sleep disturbances in a sample of persons with early dementia. J Am Geriatr Soc 58:480-86 https://doi.org/10.1111/j.1532-5415.2010.02733.x.

[37] Rwin MR, Olmstead R \& Motivala SJ (2008) Improving sleep quality in older adults with moderate sleep complaints: A randomized controlled trial of Tai Chi Chih. Sleep 31(7): 1001-8.

[38] Saber AD (2013) Insomnia among elderly in Alexandria. Master thesis, High Institute of Public Health, Alexandria University, Egypt.

[39] Sabry AA, AboZenah H \& Wafa E (2010) Sleep disorders in hemodialysis patients. Saudi J Kidney Dis Transpl 21(2): 300-305.

[40] Sheikh JI \& Yesavage JA. Geriatric Depression Scale (GDS): Recent evidence and development of a shorter version. Clinical Gerontology: A Guide to Assessment and Intervention 1986; 165-73. Available at: http//www.stanford.edu/ yesavage/GDS.html Retrieved on April 17, 2016.

[41] Shives LR (2004) Basic Concepts of Psychiatric-Mental Health Nursing. 6th ed. Philadelphia: Lippincott Williams \&Wilkins, pp $85-99$.

[42] Shokry E, Abdel-Aziz H \& Abo El-Seoud A (2014) Insomnia: Prevalence, risk factors, and its effect on quality of life among elderly in Zagazig City, Egypt. J Nursing Educ Practice 4 (8):52-64

[43] Soldatos CR, Dikeos DG \& Paparrigopoulos TJ (2000) Athens In somnia Scale: validation of an instrument based on ICD-10 criteria. Journal of Psychosomatic Research 48(6): 555-560. https://doi.org/10.1016/S0022-3999(00)00095-7.

[44] Stromberg A \& Jaarsma T (2008) Thoughts about death and perceived health status in elderly patients with heart failure. European Journal of Heart Failure 10: 608-613. https://doi.org/10.1016/j.ejheart.2008.04.011.

[45] Su TP, Huang SR \& Chou P (2004) Prevalence and risk factors of insomnia in community-dwelling Chinese elderly: a Taiwanese urban area study. Aust N Z J Psychiatry 38(9): 706-713. https://doi.org/10.1080/j.1440-1614.2004.01444.x.

[46] Suguna A, Ramakrishna G, Deepthi S, Geethu M, Mathew J, Steve P, Pooja L \& Johnson P (2015) Sleep Disturbances and Death Anxiety among the Elderly in a Rural Area of Southern Karnataka. IJHSR 5(9): 24-29

[47] Sukying C, Bhokakul V\& Udomsubpayakul U (2003) An epidemiological study on insomnia in an elderly Thai population. J Med Assoc Thai 86:316-24.
[48] Tablosky PA (2006) Gerontological Nursing. Newjersy: Pearson Prentice Hall Publication 90-102.

[49] Tanaka H, Taira K \& Arakawa M 2002. Short naps and exercise improve sleep quality and mental health in the elderly. Psychiatry Clin Neurosci 56(3):233-4. https://doi.org/10.1046/j.14401819.2002.00995.x.

[50] Taylor DJ, Mallory LJ, Lichstein KL, Riedel BW \& Bush AJ (2007) Comorbidity of chronic insomnia with medical problems. Sleep 30 (2): 213-8.

[51] Tsou MT (2013) Prevalence and risk factors for insomnia in community-dwelling elderly in northern Taiwan, J Clinical Gerontol Geriatrics 4: 75-79 https://doi.org/10.1016/j.jcgg.2013.02.002.

[52] Weronika WF, Iwona E P \& Bożena M (2016) Coexistence of insomnia and chronic diseases in over 60 year's olds. Family Medicine \& Primary Care Review 18(3): 364-367.

[53] Wong W \&, Fielding R (2011) Prevalence of insomnia among Chinese adults in Hong Kong: a population-based study. J Sleep Res 20(1):117-12. https://doi.org/10.1111/j.1365-2869.2010.00822.x. 